\title{
Analysis on the Trend of AIDS Incidence in Zhejiang, China Based on the Age-Period-Cohort Model from 2004 to 2018
}

\section{Zhenzhen Lu}

Nanjing Medical University

Weidong Ji

Xinjiang Medical University

Yi Yin

Nanjing Medical University

Xinye Jin

Nanjing Medical University

Lu Wang

Chinese Center for Disease Control and Prevention

\section{Zhongjie Li}

Chinese Center for Disease Control and Prevention

Ning Wang

Chinese Center for Disease Control and Prevention

\section{Kai Wang}

Xinjiang Medical University

Zhihang Peng ( $\nabla$ zhihangpeng@njmu.edu.cn )

Nanjing Medical University https://orcid.org/0000-0003-4372-2487

\section{Research article}

Keywords: AIDS, Age effect, Period effect, Cohort effect, Prediction

Posted Date: October 13th, 2020

DOl: https://doi.org/10.21203/rs.3.rs-90848/v1

License: (c) (1) This work is licensed under a Creative Commons Attribution 4.0 International License. Read Full License 


\section{Abstract}

Background: To predict the trend of acquired immune deficiency syndrome(AIDS) in specific age groups and to determine the objective population for AIDS screening, we explored the three transmission routes (homosexual transmission, heterosexual transmission, drug injection and others) and characterized each patients group using the Age-Period-Cohort(APC) model based on the whole, local and immigrant populations in Zhejiang, China.

Methods: The data recruited in this paper was obtained from the national "Comprehensive AIDS Prevention and Control Information System - Antiviral Therapy Management" database and the Chinese Disease Prevention and Control Information System and the Statistical Yearbook of Zhejiang, China. An APC model was used to estimate the impact of age, period and cohort on the incidence rate of AIDS, and to predict the AIDS incidence rate in specific age groups based on sexes and transmission routes.

Results: The AIDS incidence rate peaked in males between 20 and 35 years old; the incidence rate of males was higher than that of females due to the impact of period; obvious cohort effect was observed among the immigrants. In the whole and local populations, the incidence rates of males in all age groups and females in both the 35-year-old group and the whole age group were predicted to increase sharply in five years. In the immigrant population, the AIDS incidence rates of males and females in all age groups were expected to increase significantly in five years; influenced by age, the incidence of AIDS through homosexual transmission peaked between 20 and 35 years old in the whole and local populations; under the influence of period, the incidence of AIDS via homosexual transmission in the whole and local populations increased and remained stable after 2015, and the incidence of AIDS transmitted by homosexual and heterosexual routes in the immigrants also showed an increasing trend. As a result of the cohort effect, the incidence of AIDS transmitted through homosexual route among the whole and local populations peaked in 1990; the incidence of AIDS in all age groups through different transmission routes would show an upward trend over the next five years.

Conclusions: The results elucidate that there are sex differences in AIDS incidence rate, and the incidence of AIDS through various transmission routes in all groups is predicted to exhibit an upward trend in the five years to come. Effective intervention strategies should be developed and implemented by the public health departments in Zhejiang to control the epidemic of AIDS.

\section{Highlights}

1. We applied APC model to different populations in Zhejiang Province, China to analyze the incidence trend of AIDS in each group via three transmission routes.

2. The incidence rate of AIDS among 20-35 year old men and women in each group was significantly affected by age effect.

3. The incidence rate of AIDS and the increase rate in men were both higher than that in women 
4. The incidence rate of men and women in the immigrant population was expected to increase significantly in the next five years, which differs from the other populations.

5. The incidence rate of AIDS was predicted to increase in the next five years.

\section{Background}

Acquired immunodeficiency syndrome (AIDS), a global health crisis caused by human immunodeficiency virus (HIV) [1], can affect and then destroy T lymphocytes of the human immune system, making the body unable to resist infections and diseases and even leading to opportunistic infections and deaths [2]. The main routes of AIDS transmission are needle sharing among drug users, commercial sex between sex workers and clients, unsafe blood donation and vertical transmission from mother to child. By 2018, 77.3 million people had been infected with HIV and 35.4 million had died of AIDS-related diseases worldwide. Although new HIV infection cases fell by $36 \%$ between 2000 and 2017 and the number of HIVrelated deaths by $38 \%$, the number of people living with HIV increased by $14 \%$ between 2010 and 2017, indicating that the HIV/AIDS epidemic is still on the rise [3].

In China, the first case of AIDS was an Argentinean man travelling to China in 1985. The first local case of HIV infection, which was found in the same year, was a hemophiliac in Zhejiang Province in eastern China [4]. Since then, HIV/AIDS has spread throughout the country [5]. By July 2017, about 728,270 people in China had been infected with HIV/AIDS and 223,798 had died of AIDS-related diseases [6]. Currently, 780,000 people are estimated to be living with HIV/AIDS, and $21.0 \%$ of them are migrant population [7]. The high risk of HIV infection among migrants could be attributed to the following social, economic and political factors: unavailable permanent household registration(hukou), being marginalized, and insufficient health education, public health services and health insurance [8]. Although studies have shown that males have a higher incidence of AIDS than females in many countries [9-10], the sex difference is not significant in the HIV/AIDS population in China. Currently, few studies have focused on HIV/AIDS prevalence and heterogeneity among the local population and migrant population in China. Therefore, a better understanding of the sex differences in HIV/AIDS among the local and immigrant populations and the differences in the incidence of HIV/AIDS through different routes of transmission is crucial for AIDS prevention and control in China.

Zhejiang is an economically developed province along the southeast coast of China. By the end of October 2018, there had been 26,575 HIV/AIDS patients living in Zhejiang province. Sexual contact is the main infection route of HIV infection for these people, among whom $38.4 \%$ are infected through homosexual transmission [13], a major epidemic pattern of AIDS in China at present. Therefore, we chose Zhejiang and used the APC model to analyze the temporal trend of AIDS incidence in Zhejiang. Specifically, we assessed the age-period-cohort effect on the incidence of AIDS between 2004 and 2018 based on the whole population (including the local population and immigrant population) in Zhejiang, and studied the heterogeneity of AIDS incidence. In addition, we explored the characteristics of three transmission routes (homosexual, heterosexual transmission, injecting drug users and others) in these population groups. 


\section{Materials And Methods \\ Data source}

The case data of this study were from the national "Comprehensive AIDS Prevention and Control Information System - Antiviral Treatment Management" database. We reviewed and downloaded the data of HIV/AIDS cases (including sex, date of birth, confirmed date, route of infection, current address, household registration and other information) reported in Zhejiang province from 2004 to 2018. Baseline population data included two data sources: age composition of the permanent residents in Zhejiang province (i.e., $0,1,2 \ldots 8,9,10$ to 14,15 to $19 \ldots, 80-84$ years old, 85-100 years old) between 2004 and 2018 from the Chinese disease prevention and control information system; the annual local population data between 2004 and 2017 from the Zhejiang Statistical Yearbook. Due to the lack of data from the Zhejiang Statistical Yearbook 2018, we were unable to obtain the annual local population data in 2018. Therefore, the AIDS case data of 2018 were excluded from the further analysis on local and immigrant populations.

\section{Statistical analysis}

Incidence rate and mortality reflect the prevalence and death risk of the target population, as well as the health risk throughout their life[11-12]. The incidence rate and mortality cannot be estimated using the commonly-used statistical methods, so we used APC model to explore the impact of age, period and cohort on incidence rate and mortality of the disease. The APC model based on Poisson distribution is widely used in epidemiology to explore the incidence or mortality of cancer and chronic disease .

In order to facilitate the subsequent analysis and research, we processed the data of AIDS cases in the whole population, local population and the immigrant population as follows: (1) For AIDS cases in the whole and local populations, the first 15 age groups (groups aging $0-14$ years) were clustered because the overall number of cases under 15 years of age was less than $0.1 \%$. Since the overall number of AIDS cases over the age of 70 was less than $3 \%$, we grouped the last 30 age groups (groups aging $71-$ 100 years) together. We combined the whole population data (2004-2018) and local population data (2004-2017) with above two AIDS age groups respectively and divided them into 55 age groups. (2) For the AIDS cases in the immigrant population, since the number of AIDS cases between 0 and 15 years old was less than $0.1 \%$, the first 15 age groups (group aging $0-14$ years) were clustered as the group under 15 years old; since the number of AIDS cases over 50 years of age was less than $3 \%$, the last 50 age groups (group aging 51-100 years) were clustered as one group. We combined data of immigrant population with immigrant AIDS cases from 2008 to 2017, and classified them into 35 age groups.

We analyzed the AIDS patients in single age groups using APC model based on Poisson distribution. Then APC analysis was performed for the annual incidence of AIDS transmitted through homosexual, heterosexual and other routes (such as blood transfusion and intravenous drug abuse) in single age groups. The most appropriate APC was selected by minimizing bias and Akaike (AIC) information criteria [13-14]. We bootstrated the sample data in the whole data set 100 times, fitted each sample with APC 
model to check the sensitivity and fitting performance of the final APC model, and drew a probability plot (appendix Figure A2-A3). In general, all the models achieved good fitting degree.

The APC model was supposed to estimate the second order difference due to the existence of linear correlation among age, period, and cohort[15]. Logarithmic likelihood ratio tests were performed on the full and nested models of age-period, age-cohort and period-cohort to test the statistical significance of age, period and cohort effects. The t test was used to assess the difference of age effect among three groups. Finally, we used the smoothing spline to fit the future population based on sex [16] and AIDS cases transmitted through various routes. The incidence rate of AIDS in the next five years was estimated by applying the vector autoregression(VAR)[17]to the APC model.

All analyses, data visualization, and models were programmed in $\mathrm{R}$ (version 3.6.0). In particular, $\mathrm{R}$ package "apc" was used to fit the apc model and predict future trends[18].

\section{Results}

\section{Descriptive analysis on AIDS incidence}

Table 1 summarized the data on the incidence of AIDS transmitted through different routes in local and immigrant populations. Over these 15 years, a total of 27,308 AIDS cases were confirmed. Among them, there were 22,467 male cases and 4,841 female cases. For the population groups, there were 18, 287 cases in local population and 9,023 in immigrant population. There were 15,050 cases of heterosexual transmission, 11,057 cases of homosexual transmission, and 1,201 cases of other transmission routes. In males, the number of heterosexual transmitted cases ranked the highest among the local population, while for immigrant, homosexual transmitted cases ranked the highest. The overall AIDS incidence was higher in males than in females. In local population, AIDS cases over 50 years old with heterosexual transmission accounted for the most, while the cases of homosexual transmission were mostly between 21 and 35 years old. In immigrant population, AIDS cases were mainly aged 21-35 years old. In both local and immigrant populations, the number of married/cohabiting patients transmitted through heterosexuality ranked the most,while in unmarried patients, homosexual transmission was the most. Most AIDS patients were at clinical stage I, and the number of cases gradually reduced with the development of clinical stage.

In Fig. 1, we depicted the age density of AIDS incidence based on different sexes, as well as age density of AIDS incidence based on different transmission routes in the whole, local and immigrant populations. The characteristics about the incidence of AIDS were as follows. First, significant differences in age density were found between males and females, and the density of AIDS incidence in males of 2035 years old was higher than in females of the same age. Females of 45-65 years old had large-scale infection, and meanwhile the age density of AIDS incidence in females was higher than in males. In immigrant population, the age density of AIDS incidence in males and females was similar, and the largescale infection all occurred to those between 20 and 35 years old. The age density of AIDS cases via 
homosexual transmission showed cluster phenomenon and peaked between 20 and 35 years old. AIDS cases via heterosexual transmission and other routes (blood transfusion, intravenous drug abuse) showed large-scale infection between 20 and 45 years old.

Figure 2 elucidated the age distribution of AIDS cases with various marital status in Zhejiang, China. The largest number of AIDS patients were in the unmarried, and married or cohabiting groups, followed by divorced or separated groups. The unmarried AIDS cases were mostly between 15 and 35 years old, the married or cohabiting AIDS cases were mostly between 25 and 70 years old, and divorced or separated AIDS cases were mostly between 30 and 55 years old.

\section{APC analysis on incidence rate of AIDS in different populations}

Figure 3 and Fig. 4 showed the effect of age, period, and cohort on the estimation of AIDS incidence and the prediction trend in different populations. Due to the sex difference in age density of AIDS incidence, we established APC model of different populations for males and females, respectively.

\section{Age effect}

In whole population, as well as the local and immigrant populations, the incidence of AIDS in males peaked between 20 and 35 years old. In all population and the local population, the AIDS incidence in males showed a relatively stable trend after 35 years old and peaked between 60 and 70 years old again. In immigrant population, the incidence rate of AIDS in males aged over 35 decreased sharply. For females, the age effect on AIDS incidence was relative lower than in males. In whole and local females, AIDS incidence showed a slowly increasing trend between 20 and 35 years old; it remained stable after 35 years old and gradually decreased over 65 years old. In immigrant females, the incidence of AIDS peaked between 20 and 35 years old, and then decreased slowly. Based on the above results, the effect of age on AIDS incidence could be divided into two stages: over 35 years old and below 35 years old.

\section{Period effect}

Influenced by period, the AIDS incidence rate in males was higher, and increased at a faster speed than females. In the whole and local populations, the incidence in males rose sharply after 2005, reaching to $6-8$ cases per 100,000 population during the study period. The incidence in females rose slowly from 2005 to 2018 (remaining at around 1-2 cases per 100,000 population). Among immigrant population, the AIDS incidence of males rose sharply from 2008 to 2010, then leveled off between 2010 and 2012 (7-8 cases per 100,000 population), and rose sharply between 2012 and 2017 (16-17 cases per 100,000 population). The AIDS incidence rate in females leveled off throughout the study period, maintaining at $3-5$ cases per 100,000 population.

\section{Cohort effect}

The cohort effect showed a similar pattern for the whole and local populations, with the incidence of AIDS peaking in males born in 1950, 1965 and 1985-1990, and falling sharply in those born after 1990. 
The cohort effect exerted little influence on the incidence of AIDS among females. There was a small peak in the incidence of AIDS among the females born between 1985 and 1990 in the whole population, and the incidence declined slowly thereafter. In local population, the incidence of AIDS peaked in females born around 1950. The incidence of AIDS among immigrant population was significantly affected by the cohort effect, reaching a peak in both males and females born between 1985 and 1990 and declining sharply thereafter.

\section{Prediction of AIDS incidence rate in different age groups in the whole, local and immigrant populations}

Figure 4 depicted that the AIDS incidence showed an upward trend from 2004 to 2008 in males over 35 years old, below 35 years old and of all age groups, and female over 35 years old and of all age groups; it was also estimated that a sharply increasing trend would occur in the five years to come, and the final incidence in people over 35 years old would be higher than those below 35 . In the whole population, the AIDS incidence in females below 35 years old did not change greatly between 2004 and 2018 , but it was predicted to increase in the future. In local population, the incidence of females under 35 years old remained stable( 1 case per 10,000 population).In the immigrant population, the incidence of both males and females below the age of 35 , over 35 and of all age groups showed a significant upward trend during the study period (2008-2017). The incidence of both males and females below 35 was higher than those over 35 , and this trend was expected to continue in the next five years.

\section{APC analysis on the incidence of AIDS via various transmission routes in different populations}

Figures 5 and 6 showed the estimated impact of age, period and birth cohort of the whole population, including the local and immigrant populations in Zhejiang, on the incidence of AIDS through different transmission routes, and the projected trends. Considering the age density of AIDS patients with different transmission routes varied (Fig. 1), APC models were also established for each transmission routes.

\section{Age effect}

In both the whole and the local populations, the incidence of AIDS through homosexual transmission peaked significantly between 20 and 35 years old, and declined sharply when aged $>35$. The annual agespecific incidence of AIDS via homosexual transmission rose sharply before the age of 30 , followed by fluctuations, but the overall trend leveled off. The incidence of AIDS via homosexual transmission was significantly higher than that of heterosexual before 31 years of age, while after 31 years of age, the incidence of AIDS via heterosexual transmission was significantly higher than that of homosexual. Among the immigrant population, a similar pattern of age-related effects had been observed in both homosexual and heterosexual AIDS patients, with annual age-specific incidence peaking between the ages of 25 and 30 and falling sharply thereafter. The incidence of homosexual transmission was higher than heterosexual transmission before 35 years of age and higher than that of homosexual transmission 
after 35. The age effect had little impact on the incidence of AIDS transmitted by other routes in the whole, local, or immigrant populations.

\section{Period effect}

Under the influence of the period effect, the incidence of homosexual transmission in the whole and the local populations increased till 2015 and then remained stable (about 2 cases per 100,000 people). Throughout the whole study period, the incidence of AIDS via heterosexual transmission rose sharply to about 2-3 per 100,000 people, and remained higher than that via homosexual transmission. In general, the incidence of HIV/AIDS through homosexual and heterosexual transmission in the immigrant population was on the rise. In particular, from 2012 to 2016, the incidence of HIV/AIDS transmitted homosexually and heterosexually had increased rapidly, from 2 to 5-6 cases per 100,000 people. Before 2012-2013, the incidence of AIDS via transsexual transmission was higher than that via heterosexual transmission, and then turned lower after 2013. The period effect had little effect on the incidence of AIDS transmitted by other routes in the total, local and immigrant populations.

\section{Cohort effect}

In the whole and local populations, the incidence of AIDS via homosexual transmission peaked among those born in 1990. Significantly affected by the cohort effect, the incidence of AIDS via heterosexual transmission rose sharply among those born between 1940 and 1950, then fluctuated until a sharp decline among those born around 1985. In patients born before 1985, the incidence of AIDS via heterosexual transmission was significantly higher than that via homosexual transmission. And for those born after 1985, the incidence of AIDS via heterosexual transmission was significantly lower than that via homosexual transmission. In the immigrant population, the cohort effect exerted a significant impact on the incidence of AIDS via both transsexual and heterosexual transmission among those born between 1985 and 1990. The cohort effect had little impact on the incidence of AIDS transmitted by other routes, whether in the total, local, or immigrant populations.

\section{Prediction of AIDS in various age groups among different populations in future five years}

Figure 6 showed the incidence trends of AIDS via different transmission routes among the whole, local and immigrant populations, and predicted the trends over the next five years. Overall, the prevalence of AIDS, whether transmitted by homosexual, heterosexual or other routes, would be increasing over the next five years in all three age groups. The characteristics of the estimated incidence were as follows: (1) the incidence of AIDS via homosexual transmission in those below 35 years of age was nearly twice as high as in those over 35 in the whole, local and immigrant populations; (2) the incidence of AIDS via heterosexual transmission in those over 35 was significantly higher than those below 35 in the whole and immigrant populations; (3) for other modes of transmission, the incidence of AIDS in cases over 35 years old was higher than those below 35 years old in the whole and local populations. In the immigrant population, the AIDS incidence of people over 35 was lower than those below 35. 


\section{Discussion}

APC model, which is usually used for chronic diseases[19-21], can be applied to infectious diseases such as hepatitis B, tuberculosis and AIDS[22-23], as these are all long-term infections. Therefore, we used APC model to analyze the characteristics of the incidence of HIV/AIDS in both males and females in the whole, local and immigrant populations in Zhejiang, and further explored the incidence trend among HIV/AIDS patients infected by different transmission routes.

Age is an important influencing factor of AIDS. Our results showed that the incidence of AIDS was significantly affected by age in both males and females between 20 and 35 years old in the whole, local and immigrant populations, suggesting a higher AIDS risk among young people. This might be attributed to unprotected sex and multiple sexual partners[24]. A large part of people in this age group were college students, and many of them were immigrants. According to data from The Chinese Center for Disease Control and Prevention (CDC), in the past few years, the number of college students newly diagnosed with AIDS increased by $30-50 \%$ annually[25]. Our study also elucidated that people with sexually transmitted infections (especially homosexual transmission) tended to be younger[26]. Homosexual transmission has become a major way of AIDS infection among college students. Unfortunately, many homosexual male students know nothing about AIDS until they receive positive results of HIV test[27]. Therefore, it is urgent to promote health education about sex and raise the awareness of AIDS prevention among college students. The second peak of HIV/AIDS in the whole and local populations appeared at the age of 60-70, which can be attributed to the ageing population in China[28]. The elderly are more susceptible to diseases and injuries[29,30]. Some studies have shown that [31] the proportion of elderly people suffering from AIDS is much higher than before. The impact of the age effect on young immigrants of 20-35 years can also be explained by the fact that immigrants are mostly engaged in physically demanding jobs and poor housing conditions, which limit their access to health care and health information, and thus increase their risk of HIV infection [32].

The period effect showed that the incidence of HIV/AIDS in males was consistently higher than that in females during the study period, and the rate of increase in males was significantly higher than in females, which is consistent with the results of other studies[33-34]. The incidence among immigrant males was the highest, rising sharply from 2008 to 2010, then leveling off from 2010 to 2012 (7-8 per 100,000 population) and rising sharply again from 2012 to 2017 (16-17 per 100,000 population). The number of HIV/AIDS cases via homosexual and heterosexual transmission in the immigrant population continued to rise since 2008. This can be explained as follows. On one hand, due to social discrimination, a considerable proportion of men who have sex with men(MSM) leave their registered area to work and live in other areas, and thus have a high mobility[35]. The mobility of HIV-infected MSM often leads to the increase of epidemic in the destination area and even second-generation transmission. Qin et al. [36] showed that from 2008 to 2015, the number of migrant cases of HIV infection by male and male sex behavior in China increased, and the proportion of migrant, young, unmarried patients with high education level and household registration in rural areas was relatively high. On the other hand, heterosexual transmission is still a major transmission route of AIDS epidemic in Zhejiang Province. In 
addition, migrant workers form a high-risk group of HIV infection. Immigrants from rural to urban areas are at a high risk of HIV infection[37], but they lack the knowledge about HIV. Yang et al. [38] showed that about $40 \%$ immigrants did not know that the use of condoms can reduce the risk of HIV infection. Due to the current household registration (hukou) system in China, it is difficult for immigrants to obtain hukou in the destination city, especially in economically developed regions like Zhejiang[39]. And in the destination cities, health services for immigrants remain underutilized and unevenly distributed. The frequently changing government regulations on health services and prevention planning for migrant population have increased uncertainty in policy implementation and exposed migrant populations to the risk of HIV transmission[40]. A survey using national demographic data showed that areas with a higher HIV prevalence have higher rates of HIV-related education among migration population; compared with the central and western regions in China, in the eastern coastal areas with more medical and financial resources, the proportion of migrant population who received HIV education was relatively low[41]. Hence, health care resources need to be allocated to areas with large migrant populations so as to provide better health care for migrant workers.

Cohort effects reflect changes in early life environments and assume that people in the same birth cohort have equal exposure to the risk factors of a disease. Exposure to adverse environmental factors early in life may exert adverse effects on later life [42]. In the entire study cohort, the incidence of AIDS peaked in males born around 1990 and declined sharply in males born after 1990, while the incidence of AIDS in females was less affected by the cohort effect in the whole population as well as the local and immigrant populations. Furthermore, the incidence of HIV transmitted by homosexual and heterosexual sex was significantly influenced by cohort effects between 1985 and 1990, which is speculated to be related to a major epidemic among commercial plasma donors in the central and eastern provinces around 1990[2], but further research is needed.

The age density diagrams of HIV/AIDS onset and transmission routes in both sexes (Fig. 1) showed widespread HIV infections in males and females between the ages of 20 and 35; the same was found in immigrant population. Homosexual transmission of HIV/AIDS cases surged between 20 and 35 years old. AIDS cases by heterosexual transmission, blood transfusion, intravenous drug use, and other ways of transmission concentrated in population between 20 and 45 years old. As shown in Fig. 2, there was a relatively large number of unmarried AIDS patients aged 20-30. Therefore, more attention should be paid to the HIV infection of unmarried population of this age group and appropriate AIDS control programs need to be developed.

Our predictive results showed that in the whole and local populations, the incidence AIDS in males and females of all age groups would rise sharply in the next five years; in 2023, the AIDS incidence among the population of over 35 years old would be significantly higher than those under 35 years old. The incidence in women under 35 years of age in the whole population was expected to increase slightly in the future. The trend remained the same for women under 35 years of age in the local population. Among the immigrant population, both males and females under 35 and over 35 , as well as all age groups, were expected to have significant an increased incidence in the next five years. Regardless of transmission 
routes, the prevalence of HIV in all three groups will rise in the next five years. We therefore recommend that public health authorities in Zhejiang focus on the control of AIDS epidemic in the above-mentioned populations. Our findings also indicate the sex differences in the incidence of AIDS and suggest measures be devised specifically for males and females to control AIDS.

In this study, we analyzed the prevalence of HIV/AIDS in the local and immigrant populations of Zhejiang, a representative of economically developed regions, and further explored the characteristics of HIV/AIDS through different transmission routes. The main limitation of our study is the rough statistics of age distribution in the study populations, which may incur small noises and errors to the estimation. Therefore, more detailed statistics and census are needed to improve the accuracy of estimation and prediction.

\section{Conclusions}

Our results suggest that HIV/AIDS, which is transmitted mainly through sexual routes, exerts a significant impact on young people in different population groups, especially college students, and its incidence will continue to increase in the future. Due to unprotected sex, multiple sex partners, and lack of sex and AIDS prevention education, the burden of AIDS may still increase in Zhejiang in the next few years. The results of the study also indicate the sex difference in the incidence of AIDS, so measures to control the AIDS incidence should be proposed specifically for males and females. It is hoped that public health departments in Zhejiang could focus on these issues so as to better control the AIDS epidemic.

\section{Declarations}

\section{Funding}

This work was supported in part by the Natural Science Foundation of China (81673275, U1503123), the National S\&T Major Project Foundation of China (2017ZX10201101, 2018ZX10713001区 2018ZX10715002).

\section{Credit authorship contribution statement}

Zhenzhen Lu: Conceptualization, Data collection, Investigation. Weidong Ji: Writing original draft, Software, Analysis. Yi Yin: Conceptualization, Analysis. Xinye Jin : Methodology. Lu Wang: Resources. Zhongjie Li : Validation. Ning Wang : Formal analysis. Kai Wang : Writing original draft, Modification. Zhihang Peng : Supervision, Project administration.

\section{Ethical Approval}

The work were approved by the ethical committee of Nanjing Medical University ("F","CH","Nanjing Med U", "FWA00001501", "NANJING", 11/21/2004), and an IRB (Institutional Review Board) approval was given 
prior to this study. I have read and have abided by the statement of ethical standards for manuscripts submitted to BMC Infectious Diseases.

\section{Declaration of competing interest}

The authors declare no conflict of interest.

\section{References}

1. Liu $H$, Zhao M, Ren J, et al. Identifying factors associated with depression among men living with HIV/AIDS and undergoing antiretroviral therapy: a cross-sectional study in Heilongjiang, China.? Health Qual Life Outcomes. 2018;16(1):190. Published 2018 Sep 19. doi:10.1186/s12955-018-1020$\mathrm{x}$.

2. Li Z, Teng Z, Miao H. Modeling and Control for HIV/AIDS Transmission in China Based on Data from 2004 to 2016.?Comput Math Methods Med. 2017;2017:8935314. doi:10.1155/2017/8935314.

3. Tang Q, Lu H. HIV/AIDS responses in China should focus on the impact of global integration.Biosci Trends. 2018;12(5):507-509. doi:10.5582/bst.2018.01269.

4. Wu Z, Rou K, Cui H. The HIV/AIDS epidemic in China: history, current strategies and future challenges.?AIDS Educ Prev. 2004;16(3 Suppl A):7-17. doi:10.1521/aeap.16.3.5.7.35521.

5. Chen H, Luo L, Pan SW, et al. HIV Epidemiology and Prevention in Southwestern China: Trends from 1996-2017.?Curr HIV Res. 2019;17(2):85-93. doi:10.2174/1570162X17666190703163838.

6. Weine SM, Kashuba AB. Labor migration and HIV risk: a systematic review of the literature.AIDS Behav.2012;16(6):1605-1621. doi:10.1007/s10461-012-0183-4.

7. Wu J, Meng Z, Xu J, et al. New emerging recombinant HIV-1 strains and close transmission linkage of HIV-1 strains in the Chinese MSM population indicate a new epidemic risk. PLoS One. 2013;8(1):e54322. doi:10.1371/journal.pone.0054322.

8. Chinouya M, Hildreth A, Goodall D, Aspinall P, Hudson A. Migrants and HIV stigma: findings from the Stigma Index Study (UK).?Health Soc Care Community. 2017;25(1):35-42. doi:10.1111/hsc.12179.

9. Cornell M, Myer L, Kaplan R, Bekker LG, Wood R. The impact of gender and income on survival and retention in a South African antiretroviral therapy programme.?Trop Med Int Health. 2009;14(7):722731. doi:10.1111/j.1365-3156.2009.02290.x.

10. Takarinda KC, Harries AD, Shiraishi RW, Mutasa-Apollo T, Abdul-Quader A, Mugurungi O. Genderrelated differences in outcomes and attrition on antiretroviral treatment among an HIV-infected patient cohort in Zimbabwe: 2007-2010.?Int J Infect Dis. 2015;30:98-105.

doi:10.1016/j.ijid.2014.11.009

11. Luo G, Zhang Y, Guo P, Wang L, Huang Y, Li K. Global patterns and trends in stomach cancer incidence: Age, period and birth cohort analysis.? Int J Cancer. 2017;141(7):1333-1344. doi:10.1002/ijc.30835. 
12. Wang J, Bai Z, Wang Z, Yu C. Comparison of Secular Trends in Cervical Cancer Mortality in China and the United States: An Age-Period-Cohort Analysis.? Int J Environ Res Public Health. 2016;13(11):1148. Published 2016 Nov 17. doi:10.3390/ijerph13111148.

13. Holford TR. Understanding the effects of age, period, and cohort on incidence and mortality rates.? Annu Rev Public Health. 1991;12:425-457. doi:10.1146/annurev.pu.12.050191.002233.

14. "A new look at the statistical model identification."?Automatic Control IEEE Transactions on? 19.6(1974):716-723.

15. Kuang, D. . "Forecasting with the age-period-cohort model and the extended chain-ladder model." Biometrika 95.4(2008):p.987-991.

16. Green PJ Silverman BW. Nonparametric Regression and Generalized Linear Models: A Roughness Penalty Approach. NewYork: Chapman and Hall/CRC. 2013, Hastie TJ Tibshirani RJ. Generalized Additive Models. New York: Chapman and Hall/CRC. 2013.

17. Rob Mahoney. "Macroeconomics and Reality." Review of Middle East Economics \\& Finance 48.2(1998):1-48.

18. Nielsen, B. apc: An R package for age-period-cohort analysis. R Journal. 2015;7:52-64. Open access: https://journal.r-project.org/archive/2015/RJ-2015-020/RJ-2015-020.pdf.

19. Wong IO, Schooling CM, Cowling BJ, Leung GM. Breast cancer incidence and mortality in a transitioning Chinese population: current and future trends. Br J Cancer. 2015;112(1):167-170. doi:10.1038/bjc.2014.532.

20. "Inference and forecasting in the age-period-cohort model with unknown exposure with an application to mesothelioma mortality." Journal of the royal statistical society, Series A. Statistics in society (2015).

21. Martínez-Miranda MD, Nielsen B, Nielsen JP. Simple benchmark for mesothelioma projection for Great Britain. Occup Environ Med. 2016;73(8):561-563. doi:10.1136/oemed-2015-103303.

22. Verdecchia A, Mariotto A, Capocaccia R, Mariotti S. An age and period reconstruction of the HIV epidemic in Italy. Int J Epidemiol. 1994;23(5):1027-1039. doi:10.1093/ije/23.5.1027.

23. Houweling H, Wiessing LG, Hamers FF, Termorshuizen F, Gill ON, Sprenger MJ. An age-period-cohort analysis of 50,875 AIDS cases among injecting drug users in Europe. Int $\mathrm{J}$ Epidemiol. 1999;28(6):1141-1148. doi:10.1093/ije/28.6.1141.

24. Franco E, Bagnato B, Marino MG, Meleleo C, Serino L, Zaratti L. Hepatitis B: Epidemiology and prevention in developing countries.?World J Hepatol. 2012;4(3):74-80. doi:10.4254/wjh.v4.i3.74.

25. Li G, Jiang Y, Zhang L. HIV upsurge in China's students. Science. 2019;364(6442):711. doi:10.1126/science.aay0799.

26. Zhang Y, Liu D, Yang Z, et al. Epidemiological characteristics of foreign HIV/AIDS cases live in Shenzhen during 2004-2017. Electronic Journal of Emerging Infectious Diseases. 2019, 4(3): 165168. 
27. Zou H, Tucker JD, Fan S, et al. Learning about HIV the hard way: HIV among Chinese MSM attending university. Lancet Infect Dis. 2018;18(1):16-18. doi:10.1016/S1473-3099(17)30711-9\\#AWSXZ45.

28. Chen WQ, Zheng RS, Zhang SW, Zeng HM, Zou XN, He J. Zhonghua Zhong Liu Za Zhi. 2017;39(1):6066. doi:10.3760/cma.j.issn.0253-3766.2017.01.012.

29. Gouveia N, Fletcher T. Time series analysis of air pollution and mortality: effects by cause, age and socioeconomic status. J Epidemiol Community Health. 2000;54(10):750-755.

doi:10.1136/jech.54.10.750.

30. Jones RP. Age-specific and year of birth changes in hospital admissions during a period of unexplained higher deaths in England.?Eur J Intern Med. 2017;45:2-4. doi:10.1016/j.ejim.2017.09.039.

31. Xing J, Li YG, Tang W, et al. HIV/AIDS epidemic among older adults in China during 2005-2012: results from trend and spatial analysis. Clin Infect Dis. 2014;59(2):e53-e60. doi:10.1093/cid/ciu214.

32. Tiruneh K, Wasie B, Gonzalez H. Sexual behavior and vulnerability to HIV infection among seasonal migrant laborers in Metema district, northwest Ethiopia: a cross-sectional study. BMC Public Health. 2015;15:122. Published 2015 Feb 11. doi:10.1186/s12889-015-1468-0.

33. Yijuan, Luo, et al. "Epidemiological characteristics of students HIV/AIDS cases in Shenzhen, 20082018."?China Tropical Medicine?(2019).

34. Gao D, Zou Z, Dong B, et al. Secular trends in HIV/AIDS mortality in China from 1990 to 2016: Gender disparities.?PLoS One. 2019;14(7):e0219689. Published 2019 Jul 18. doi:10.1371/journal.pone.0219689.

35. Mi G, Ma B, Kleinman N, et al. Hidden and Mobile: A Web-based Study of Migration Patterns of Men Who Have Sex With Men in China. Clin Infect Dis. 2016;62(11):1443-1447. doi:10.1093/cid/ciw167.

36. Qin Q Q., Guo W., Wang L Y., Ding Z W., Cai C., Cui Y., Sun J P.(2016). [The characteristics of HIVpositive men who have sex with men in China and predictors of their migration, 2008-2015]. Zhonghua Yu Fang Yi Xue Za Zhi, 50(11), 938-942. doi:10.3760/cma.j.issn.0253-9624.2016.11.004.

37. Li W, Jiang J, Su J, et al. Commercial Sexual Behaviors Among Male Rural-to-Urban Migrants in Western China: Implications for HIV Prevention. Asia Pac J Public Health. 2017;29(5):388-400. doi:10.1177/1010539517709029.

38. Yang B, Wu Z, Schimmele CM, Li S. HIV knowledge among male labor migrants in China.?BMC Public Health. 2015;15:323. Published 2015 Apr 2. doi:10.1186/s12889-015-1653-1.

39. National Bureau of Statistics of China. China Statistical Yearbook 2016. 2016. www.stats.gov.cn/english/. Accessed 14 June 2019.

40. Hu X, Cook S, Salazar MA. Internal migration and health in China.?Lancet. 2008;372(9651):17171719. doi:10.1016/S0140-6736(08)61360-4.

41. Zhu Z, Guo M, Petrovsky DV, Dong T, Hu Y, Wu B. Age and regional disparity in HIV education among migrants in China: migrants population dynamic monitoring survey, 2014-2015. Int J Equity Health. 2019;18(1):104. Published 2019 Jul 3. doi:10.1186/s12939-019-0999-x. 
42. Wang F, Mubarik S, Zhang Y, et al. Long-Term Trends of Liver Cancer Incidence and Mortality in China 1990-2017: A Joinpoint and Age-Period-Cohort Analysis. Int J Environ Res Public Health. 2019;16(16):2878. Published 2019 Aug 12. doi:10.3390/ijerph16162878.

\section{Table}

Table 1 AIDS cases transmitted via various routes in local and immigrant populations

\begin{tabular}{|c|c|c|c|c|c|c|c|}
\hline & & \multirow{2}{*}{\multicolumn{2}{|c|}{$\begin{array}{l}\text { Heterosexual transmission } \\
\qquad(N=15050)\end{array}$}} & \multirow{2}{*}{\multicolumn{2}{|c|}{$\begin{array}{l}\text { Homosexual transmission } \\
\qquad(N=11057)\end{array}$}} & \multirow{2}{*}{\multicolumn{2}{|c|}{$\begin{array}{l}\text { other } \\
\text { (N=1201) }\end{array}$}} \\
\hline & & & & & & & \\
\hline & & no. & $\%(95 \% \mathrm{Cl})$ & no. & $\%(95 \%$ C 1$)$ & no. & $\$(95 \%$ C1) \\
\hline \multicolumn{8}{|l|}{ Sex } \\
\hline \multirow[t]{2}{*}{ Local } & Male & 7927 & $52.67(51.87-53.47)$ & 6795 & $61.45(60.54-62.36)$ & 584 & $48.63(45.76-51.49)$ \\
\hline & Female & 2812 & $18.68(18.06-19.32)$ & 5 & $0.05(0.01-0.11)$ & 162 & $13.49(11.61-15.56)$ \\
\hline \multirow[t]{2}{*}{ Immigrant } & Male & 2582 & $17.16(16.56-17.77)$ & 4252 & $38.46(37.55-39.37)$ & 327 & $27.23(24.73-29.84)$ \\
\hline & Female & 1729 & $11.49(10.98-12.01)$ & 5 & $0.05(0.01-0.11)$ & 128 & $10.66(8.97-12.54)$ \\
\hline \multicolumn{8}{|c|}{ Age groups } \\
\hline \multirow[t]{4}{*}{ Local } & 0.20 & 202 & $1.34(1.16-1.54)$ & 552 & $4.99(4.59-5.41)$ & 30 & $2.50(1.69-3.55)$ \\
\hline & $21-35$ & 2643 & $17.56(16.96-18.18)$ & 3853 & $34.85(33.96-35.74)$ & 245 & $20.40(18.15-22.79)$ \\
\hline & $36-50$ & 3346 & $22.23(21.57-22.91)$ & 1681 & $15.20(14.54-15.89)$ & 253 & $21.07(18.79-23.48)$ \\
\hline & overso & 4548 & $30.22(29.49-30.96)$ & 714 & $6.46(6.01-6.93)$ & 218 & $18.15(16.01-20.45)$ \\
\hline \multirow[t]{4}{*}{ Immigrant } & 0.20 & 195 & $1.30(1.12-1.49)$ & 251 & $2.27(2.00-2.57)$ & 23 & $1.92(1.22-2.86)$ \\
\hline & $21-35$ & 2190 & $14.55(13.99-15.13)$ & 2796 & $25.29(24.48-26.11)$ & 242 & $20.15(17.91-22.53)$ \\
\hline & $36-50$ & 1532 & $10.18(9.70-10.67)$ & 1094 & $9.89(9.34-10.47)$ & 163 & $13.57(11.68-15.64)$ \\
\hline & overso & 394 & $2.62(2.37-2.89)$ & 116 & $1.05(0.87-1.26)$ & 27 & $2.25(1.49-3.25)$ \\
\hline
\end{tabular}

Marital status

\begin{tabular}{|c|c|c|c|c|c|c|c|}
\hline \multirow[t]{5}{*}{ Local } & Unmarried & 1768 & $11.75(11.24-12.27)$ & 4243 & $38.37(37.47-39.29)$ & 186 & $15.49(13.49-17.66)$ \\
\hline & Married/Cohabiting & 6888 & $45.77(44.97-46.57)$ & 1739 & $15.73(15.05-16.42)$ & 430 & $35.80(33.09-38.59)$ \\
\hline & Divorced/Separated & 1608 & $10.68(10.20-11.19)$ & 768 & $6.95(6.48-7.44)$ & 94 & $7.83(6.37-9.49)$ \\
\hline & Widowed & 460 & $3.06(2.79-3.34)$ & 39 & $0.35(0.25-0.48)$ & 21 & $1.75(1.09-2.66)$ \\
\hline & Unknown & 18 & $0.12(0.07-0.19)$ & 11 & $0.10(0.05-0.18)$ & 15 & $1.25(0.70-2.05)$ \\
\hline \multirow[t]{5}{*}{ Immigrant } & Unmarried & 1152 & $7.65(7.23-8.09)$ & 2713 & $24.54(23.74-25.35)$ & 147 & $12.24(10.44-14.23)$ \\
\hline & Married/Cohabiting & 2390 & $15.88(15.30-16.47)$ & 987 & $8.93(8.40-9.47)$ & 236 & $19.65(17.44-22.01)$ \\
\hline & Divorced/Separated & 648 & $4.31(3.99-4.64)$ & 542 & $4.90(4.51-5.32)$ & 53 & $4.41(3.32-5.73)$ \\
\hline & Widowed & 110 & $0.73(0.60-0.88)$ & 11 & $0.10(0.05-0.18)$ & 10 & $0.83(0.40-1.53)$ \\
\hline & Unknown & 11 & $0.07(0.04-0.13)$ & 4 & $0.04(0.01-0.09)$ & 9 & $0.75(0.34-1.42)$ \\
\hline
\end{tabular}

Clinical stage

\begin{tabular}{lccccccc}
\hline Local & Clinical phase I & 6347 & $42.17(41.38-42.97)$ & 4187 & $37.87(36.96-38.78)$ & 512 & 42.63 (39.81-45.48) \\
& & & & & & & \\
& Clinical phase II & 1964 & $13.05(12.52-13.60)$ & 1534 & $13.87(13.23-14.53)$ & 101 & $8.41(6.90-10.12)$ \\
& & & & & & & \\
& Clinical phase III & 1492 & $9.91(9.44-10.40)$ & 699 & $6.32(5.88-6.79)$ & 87 & $7.24(5.84-8.86)$ \\
& Clinical phase IV & 936 & $6.22(5.84-6.62)$ & 380 & $3.43(3.10-3.79)$ & 46 & $3.83(2.82-5.08)$ \\
\hline Immigrant & Clinical phase I & 2861 & $19.01(18.39-19.65)$ & 2560 & $23.15(22.37-23.95)$ & 312 & $25.98(23.52-28.56)$ \\
& Clinical phase II & 899 & $5.97(5.60-6.36)$ & 1185 & $10.72(10.15-11.31)$ & 94 & $7.83(6.37-9.49)$ \\
& Clinical phase III & 352 & $2.34(2.10-2.59)$ & 345 & $3.12(2.80-3.46)$ & 35 & $2.91(2.04-4.03)$ \\
& Clinical phase IV & 199 & $1.32(1.15-1.52)$ & 167 & $1.51(1.29-1.76)$ & 14 & $1.17(0.64-1.95)$ \\
\hline
\end{tabular}




\section{Figures}
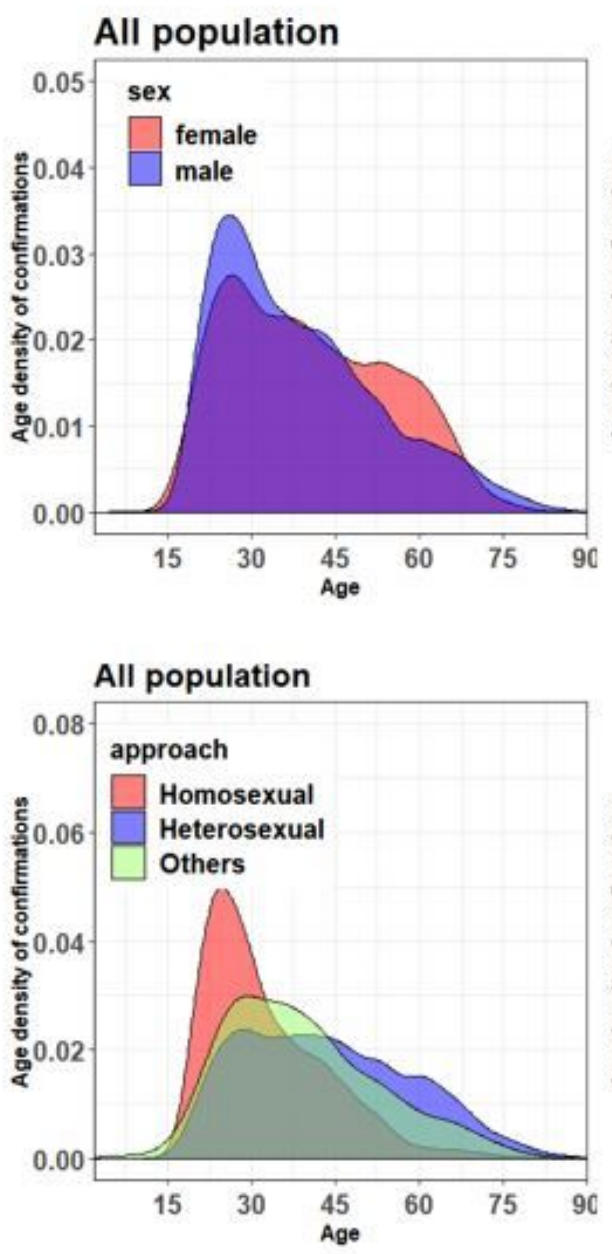

(a)Local poplution

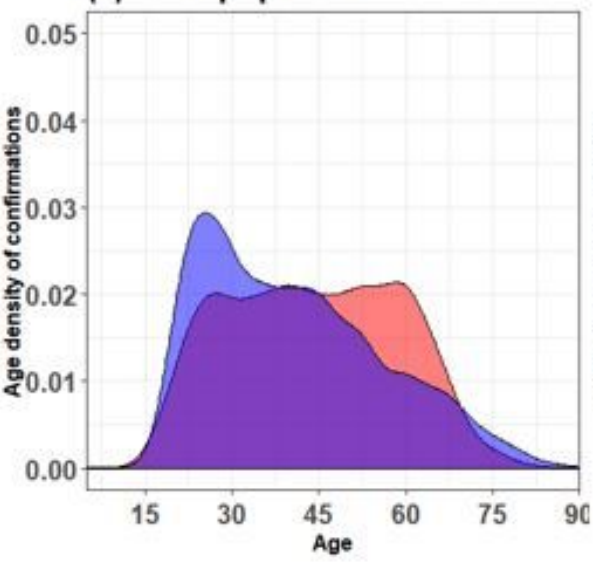

(a)Local poplution

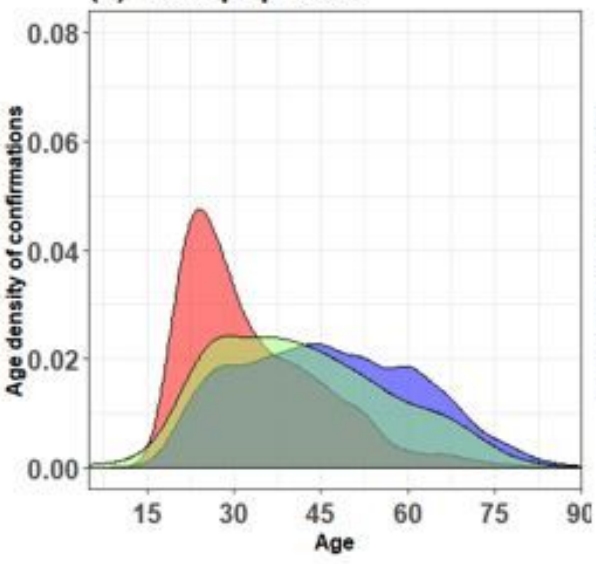

(b)Immigrant population

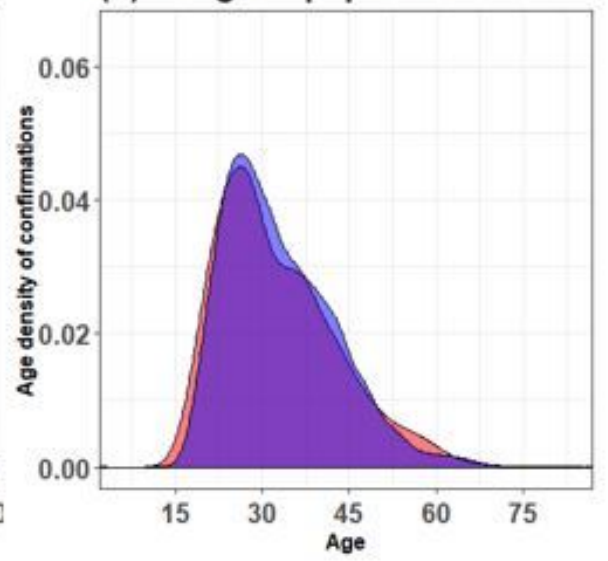

(b)Immigrant population

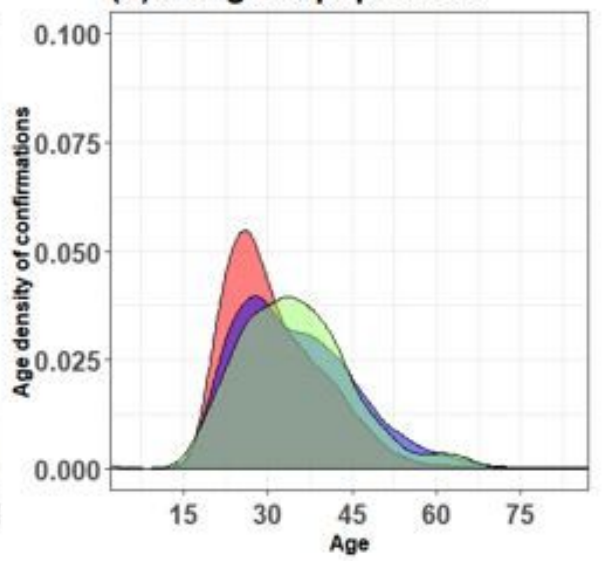

\section{Figure 1}

The AIDS age density in males and females, and age density of AIDS via different transmission routes in the whole population (including a. local population and b. immigrant population). In the diagrams above, blue and red represent the age density of males and females, respectively. In the diagrams below, red, blue and green represent the age density of AIDS via homosexual, heterosexual, and other transmission routes, respectively 


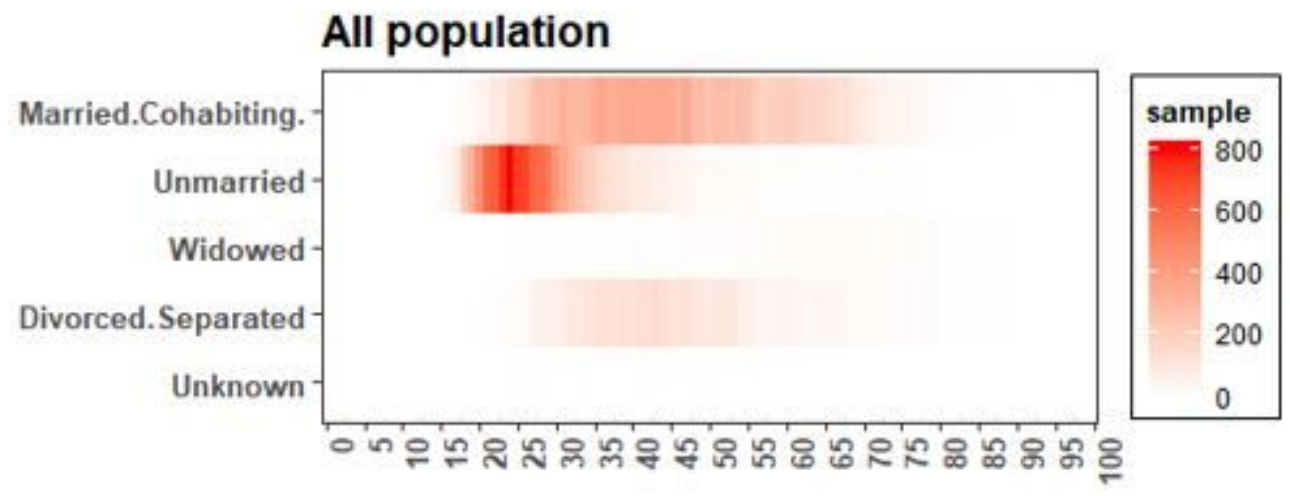

(a)Local popluation

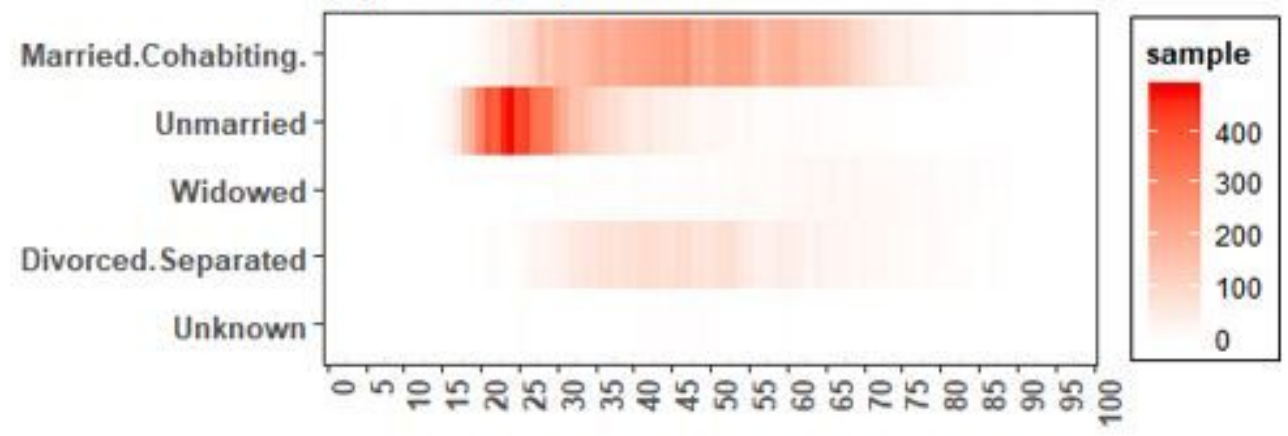

(b)Immigrant population

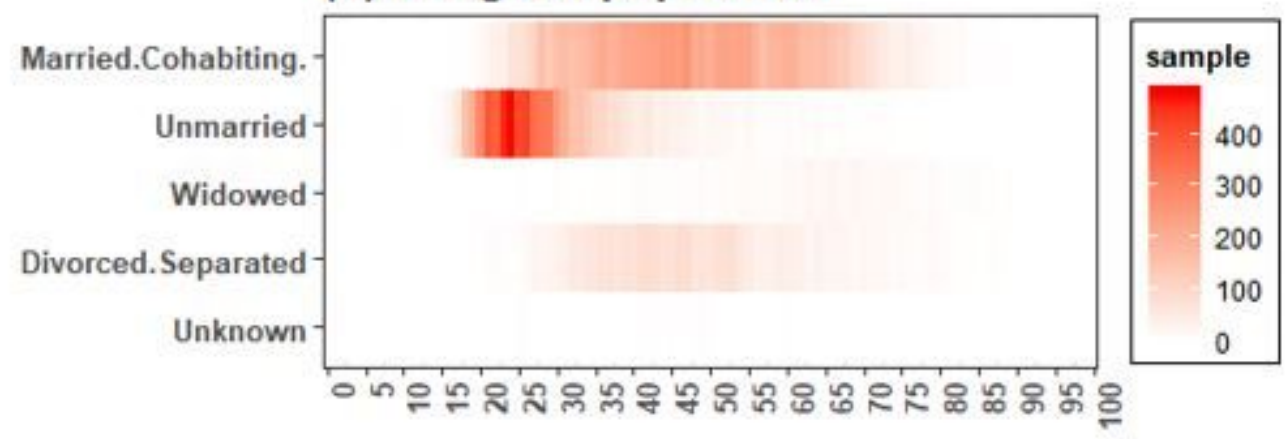

Figure 2

Age distribution of AIDS cases with different marital status in Zhejiang, China 

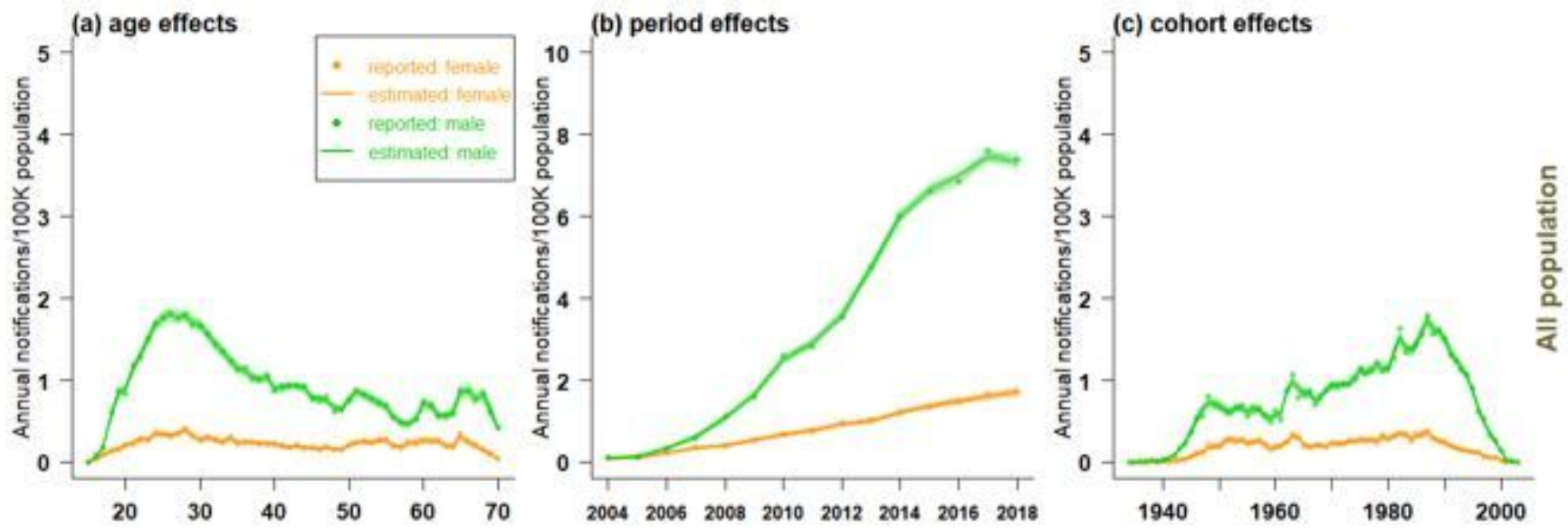

(a) age effects

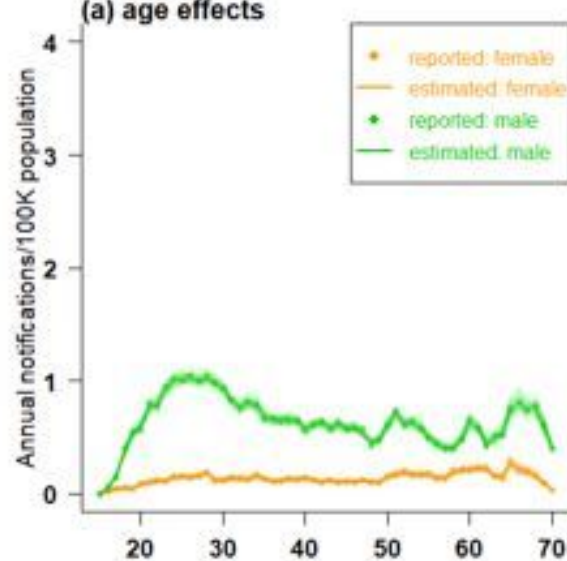

(b) period effects

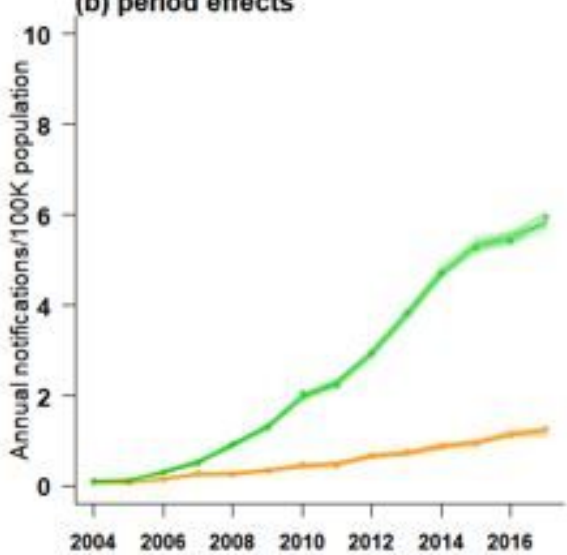

(c) cohort effects
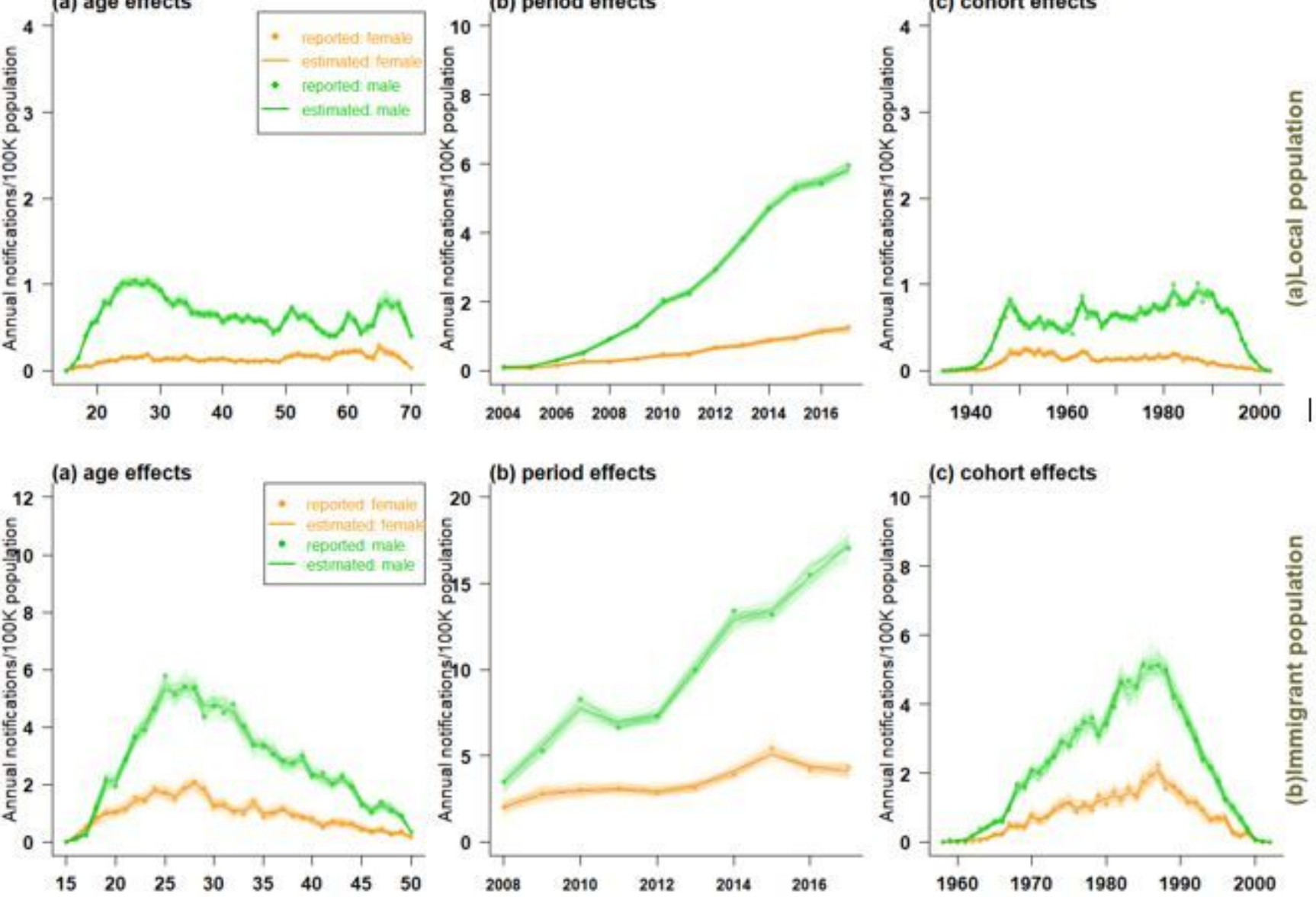

\section{Figure 3}

The effect of age(left), period((middle), and cohort(right) on the estimation of AIDS incidence in all populations (a: local population, b: immigrant population) 

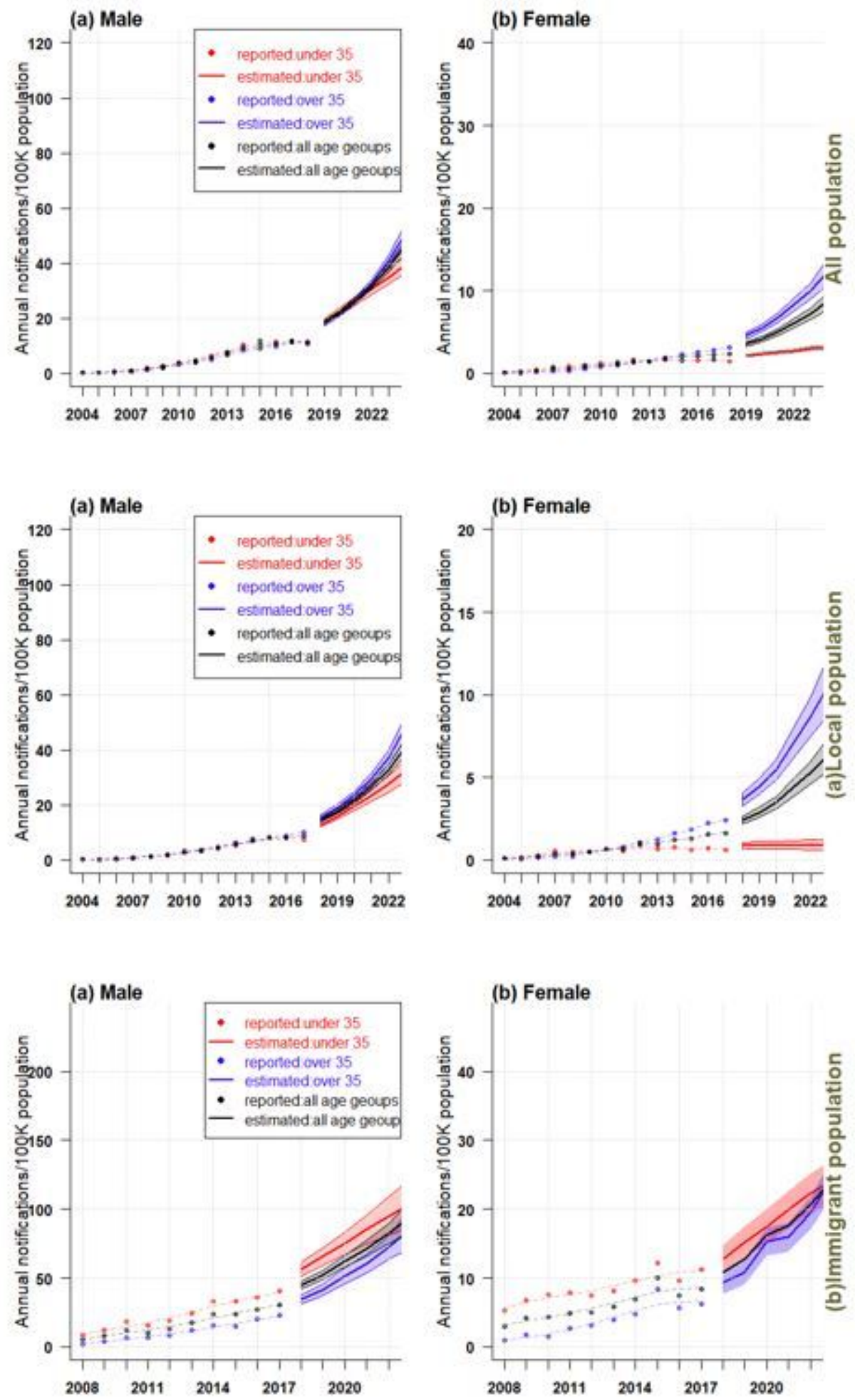

\section{Figure 4}

Trends of AIDS incidence and projected trends over the next five years in the whole population of Zhejiang , China (a. local population, b immigrant population). 

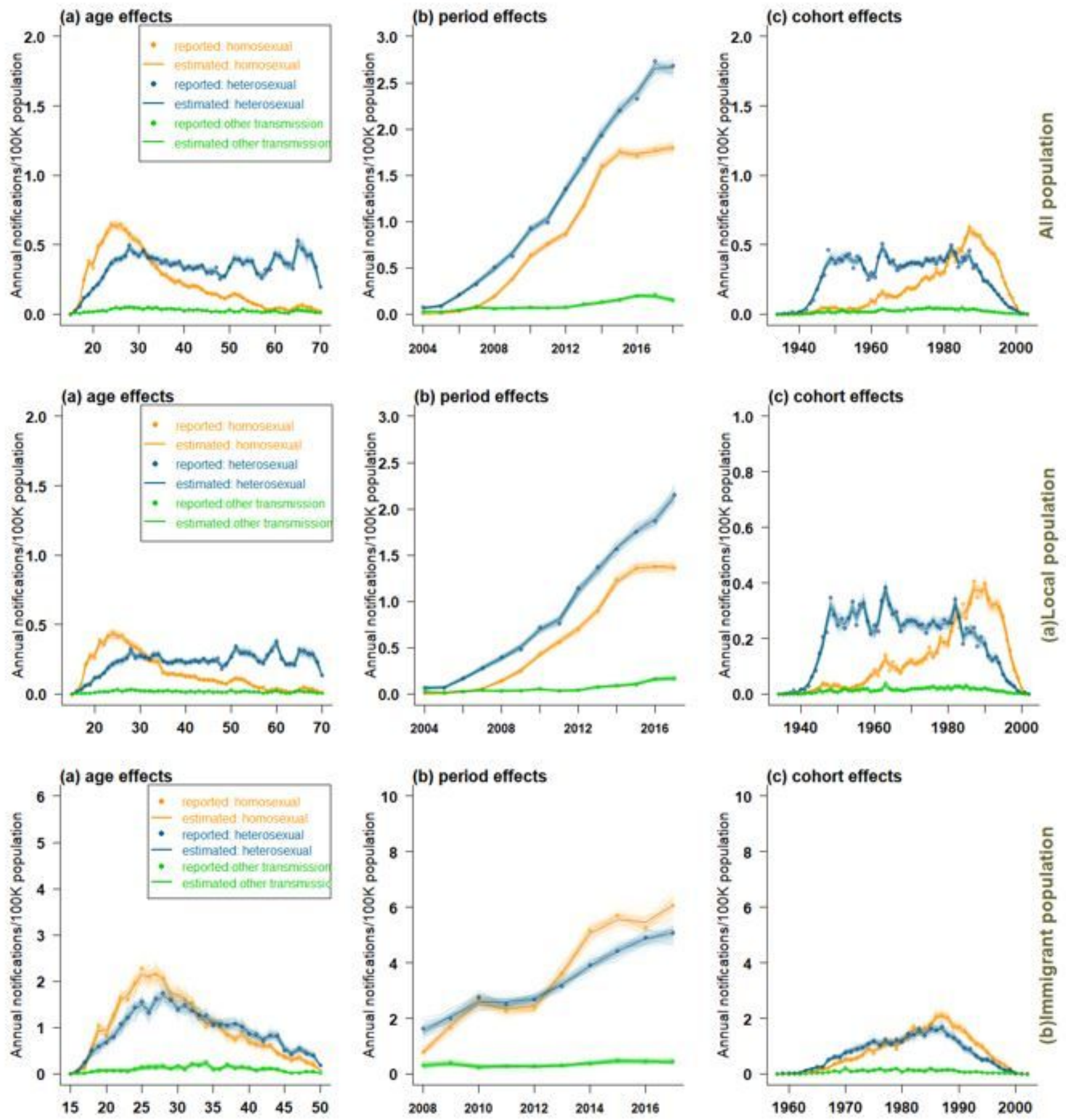

Figure 5

Estimated impact of age (left column), period (middle column) and birth cohort (right column) on the incidence of AIDS by different transmission routes in the entire population (including a. local population and b. immigrant population) of Zhejiang Province, China. 
(a) Homosexual transmission

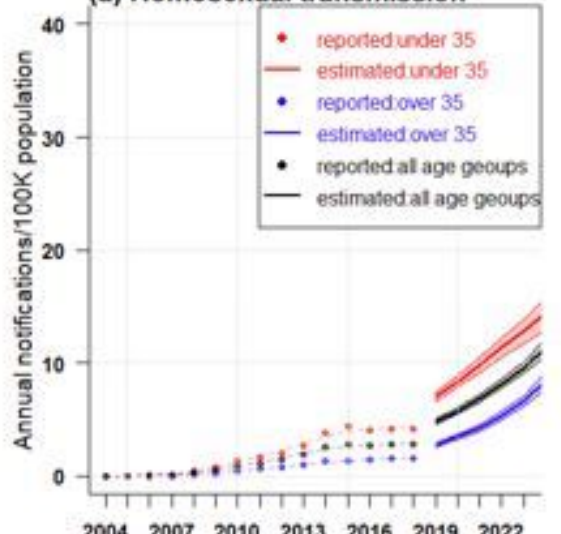

(a) Homosexual transmission

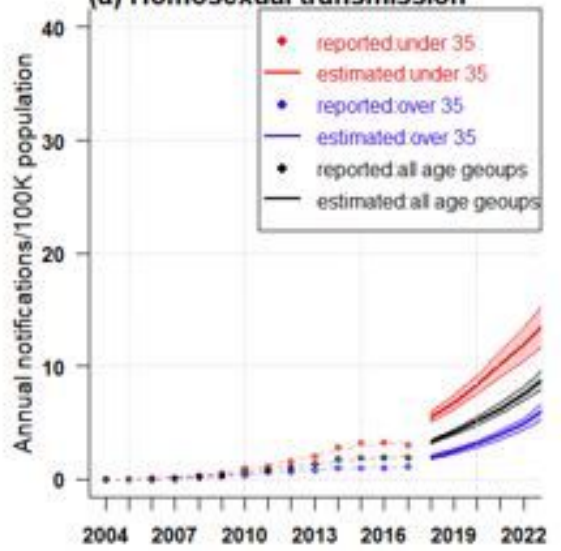

(a) Homosexual transmission

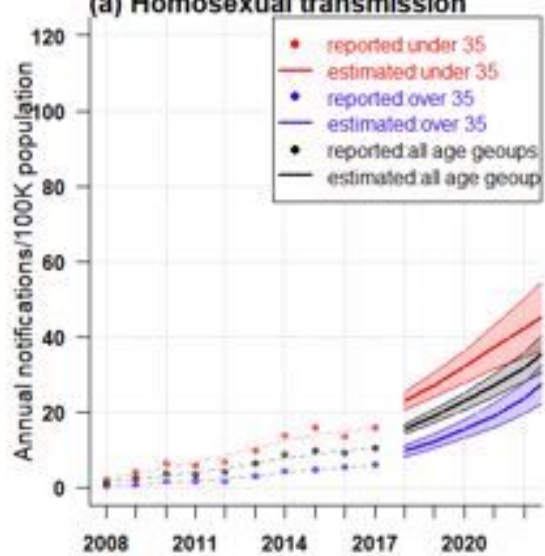

(b) Heterosexual transmission

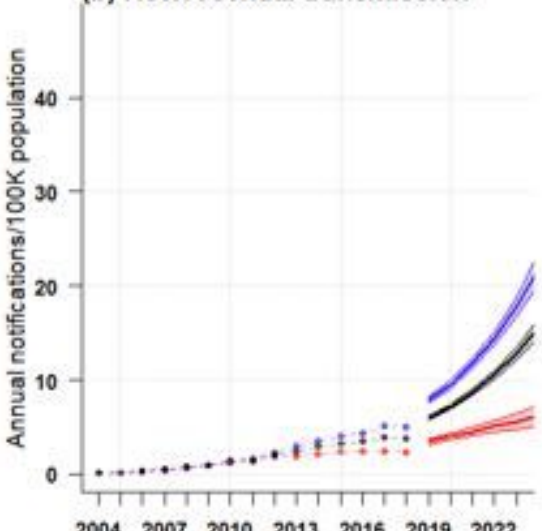

(b) Heterosexual transmission

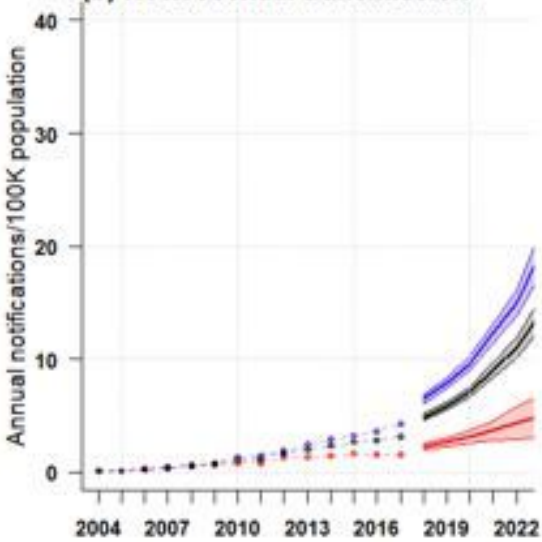

(b) Heterosexual transmission
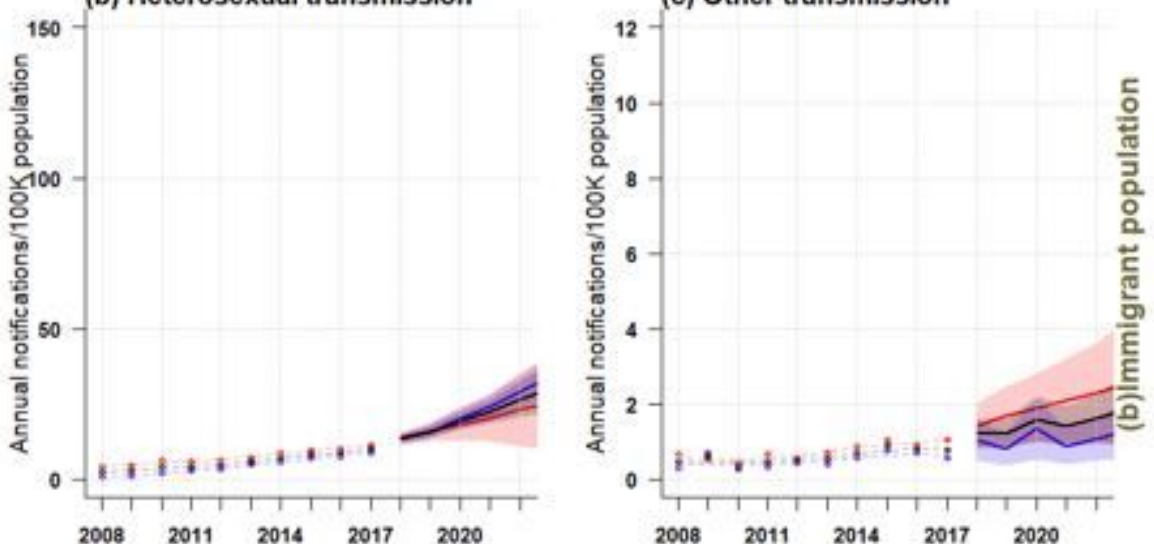

(c) Other transmission

(c) Other transmission

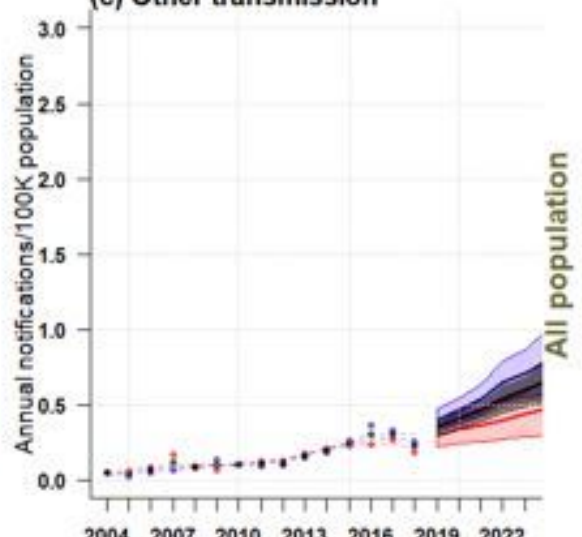

(c) Other transmission

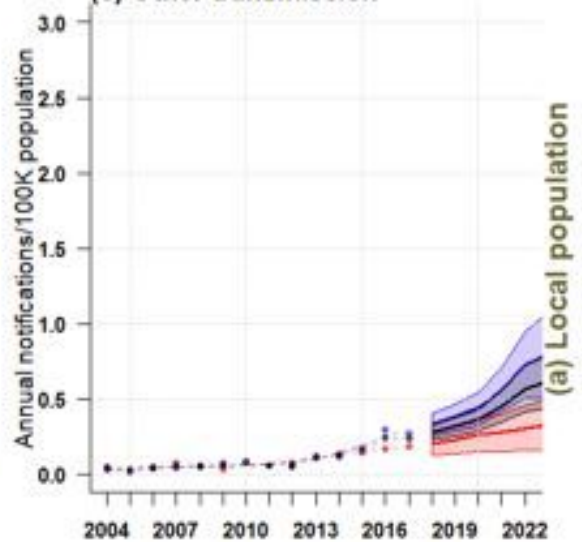

$\begin{array}{lllllll}2004 & 2007 & 2010 & 2013 & 2016 & 2019 & 2022\end{array}$

$$
\text { 高 }
$$

\section{Figure 6}

Trends in the incidence of AIDS via different transmission routes in Zhejiang Province, China (including a. local and b. immigrant populations), and projected trends over the next five years.

\section{Supplementary Files}

This is a list of supplementary files associated with this preprint. Click to download. 
- Appendix.docx

- Supplementarymaterial.docx

Page 22/22 